Nevertheless, Ethics and Animals is likely to take its place in the literature as a brave beginning to the genuine interdisciplinary debate which must follow if any real progress is to be made in our attitudes to and treatment of other animals. At last, enough people from enough points of view are prepared to treat the questions seriously. It would be a monstrous piece of philosophical negligence to let the opportunity slip away.

JUDITH HUGHES

Department of Philosophy, University of Newcastle Upon Tyne

\section{Genetic Prophecy: Beyond the Double Helix}

Harsanyi Z, Hutton R. London, Toronto, Sydney, New York, Granada, $1982, £ 8.95$

This book is the product of the collaboration of a geneticist and a medical and scientific writer. It is racily written with many anecdotes but it serves to provide an introduction to a serious subject and to point out considerable potentialities for preventive medicine.

The authors divide the work into three parts, respectively on prophecy, health and behaviour. The first, on prophecy, outlines the history of empirical observations resulting in a view of medicine as the practice of identifying predispositions to disease in certain people or classes of people. This has led to the development of genetic analysis and counselling, a practice that may well burgeon in the coming years. The second part, on health, presents the methodology for identifying genetic markers, those recognisable characteristics which enable the medical scientist to detect the existence of a particular gene and which may lead to prediction of susceptibility to a particular disease. A list of those diseases associated with human leukocyte antigen genetic markers is given. There are over eighty, the numbers rising annually as research progresses. To be sure there are great lacunae, as for instance between knowing a person is at risk from a disease and making a firm diagnosis ahead of time, but the prospects for this science are exciting and clearly hopeful for cancer treatment, prevention of occupational diseases and nutrition as well as the prevention of genetic defects being transmitted in human reproduction.

It is when we come to the third part of this book, on behaviour, that we enter the ethical field. This is especiall noticeable whenever a discussion takesn place on selective mating using artificia $\overrightarrow{\mathrm{P}}$. insemination by donor with a view tôn producing particularly intelligent offspring. But ethical considerations? arise as soon as one postulates a crimina $\Phi$ chromosome, and the entire subject of genetic screening raises a host of probs] lems, ethical as well as medical. As th $\bar{\Phi}$ late C S Lewis said 'Each new powe? won by man is a power over man as well'. The authors are aware of this and discuss the abuse of power, the propen:sity for people to stereotype and stig $\vec{\epsilon}$ matise others and the price of success i genetic prophecy. They raise the ques? tions, it remains for others to provid $\Phi$ the answers. An appendix lists th $\vec{\ominus}$ addresses of UK genetic advisoris centres.

This is a disturbing book. It is inforer mative and makes good reading, and $\$$ introduces the reader to an exciting. world of possibilities. Now is the times for the serious appraisal of the social an $\$$ moral implications to take place.

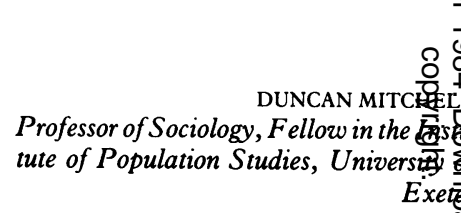

